УДК 338.22

\title{
Е.Н. Яковлева
}

\section{ФИНАНСОВОЕ ОБЕСПЕЧЕНИЕ УПРАВЛЕНИЯ КЛИМАТИЧЕСКОЙ БЕЗОПАСНОСТЬЮ}

В XXI в. изменение климата становится ключевым ограничением устойчивого развития отраслей, регионов, стран, мирового сообщества в целом. Поэтому управление климатическими рисками требует все более серьезной финансовой поддержки как для компенсации ущерба от опасных гидрометеорологических явлений, так и для проведения политики снижения антропогенных выбросов парниковых газов и адаптации к происходящим изменениям. В статье изучены основные источники финансирования управления климатической безопасностью в России и зарубежных странах. Выявлены их положительные стороны и проблемы практического использования. Каждый финансовый инструмент рассмотрен с позиций регулирующего воздействия на субъекты рыночной экономики и климатические риски. Показано, что ряд применяемых на постоянной основе или в качестве эксперимента элементов фискальной политики в России требуют доработки или замены. Предложены практические рекомендации по улучшению ситуации, в том числе применение инновационного для нашей страны инструментария (климатический инновационный банк, погодные и температурные опционы и др.). Авторские рекомендации нацелены на изменение вектора климатического регулирования с государственного патернализма на имплементацию предпринимательской инициативы посредством создания действенных рыночных стимулов. Результатом станет не только снижение выбросов парниковых газов и энергоемкости экономики, но и повышение прибыльности и конкурентоспособности, инвестиционной привлекательности организаций, территориальных образований, страны, а также увеличение занятости и благосостояния населения, национального богатства Российской Федерации.

Ключевые слова: климатическая безопасность, климатические риски, финансовые ресурсы, налоги, углеродный сбор, амортизация, кредит, страхование, хеджирование, лизинг, резервирование.

DOI: $10.35634 / 2412-9593-2021-31-6-1032-1040$

Изменение климата является сегодня одним из барьеров социально-экономического развития, причем некоторые ученые называют этот дефицит доминирующим (например, Н. Пайджон и Б. Фишхо категорично высказываются, что судьба мира находится в руках климатологов [1]). И, действительно, обсуждаемый в научной литературе спектр наблюдаемых и потенциальных последствий климатических изменений необычайно широк: от прямого ущерба наиболее уязвимым отраслям (сельскому, лесному, водному, жилищно-коммунальному хозяйству, строительству, энергетике и туризму), угроз продовольственной безопасности, до негативного влияния на физическое [2] и даже психическое [3] здоровье населения. До сих пор дискуссионными остаются вопросы причин и обратимости изменения климата [4], однако, на наш взгляд, независимо от факторов - естественных или антропогенных, сам процесс неостановим. Тенденции увеличения количества опасных гидрометеорологических явлений, а вместе с ними и эколого-экономического ущерба (для России тренды отражены на рисунке), генерируют дополнительные финансовые угрозы функционирования домохозяйств, предприятий, секторов и в целом народного хозяйства [5].

По данным Росстата (см. рис.) за период 2011-2019 гг. произошел рост ОГЯ на 18,8 \%, из них, нанесших значительный ущерб выросли на 7,5%. Доля явлений с ущербом колеблется от 38 до 48 \%. Поэтому актуальность развития финансовых механизмов защиты от климатических рисков и адаптации субъектов экономики к изменению климата перманентно растет.

Для большинства литературных источников характерно узкое внимание локализованным проблемам и источникам финансирования управления климатическими рисками. Однако масштабность обсуждаемых проблем требует более системного и комплексного подхода. Практика управления в нашей стране и за рубежом также не сформировала целостного финансового механизма в обозначенной сфере, что является производной от проблемы отсутствия адекватного внимания климатическим угрозам. В качестве основных причин, почему глобальное потепление не воспринимается как кризис, называются две: временной и пространственный разрывы [7]. Первый заключается в том, что существует временная задержка между накоплением парниковых газов и последствиями такого накопления. Это ослабляет внимание к проблеме как со стороны социума, так и политических лидеров: последние избираются каждые 4-6 лет, а временные рамки последствий глобального потепления со- 
ставляют приблизительно 102 года [7]. Пространственный разрыв состоит в несоответствии масштабов климатических рисков и управления ими: лица, принимающие решения на национальном, региональном, местном и корпоративном уровнях должны знать, как глобальное изменение климата вписывается в зону их ответственности.
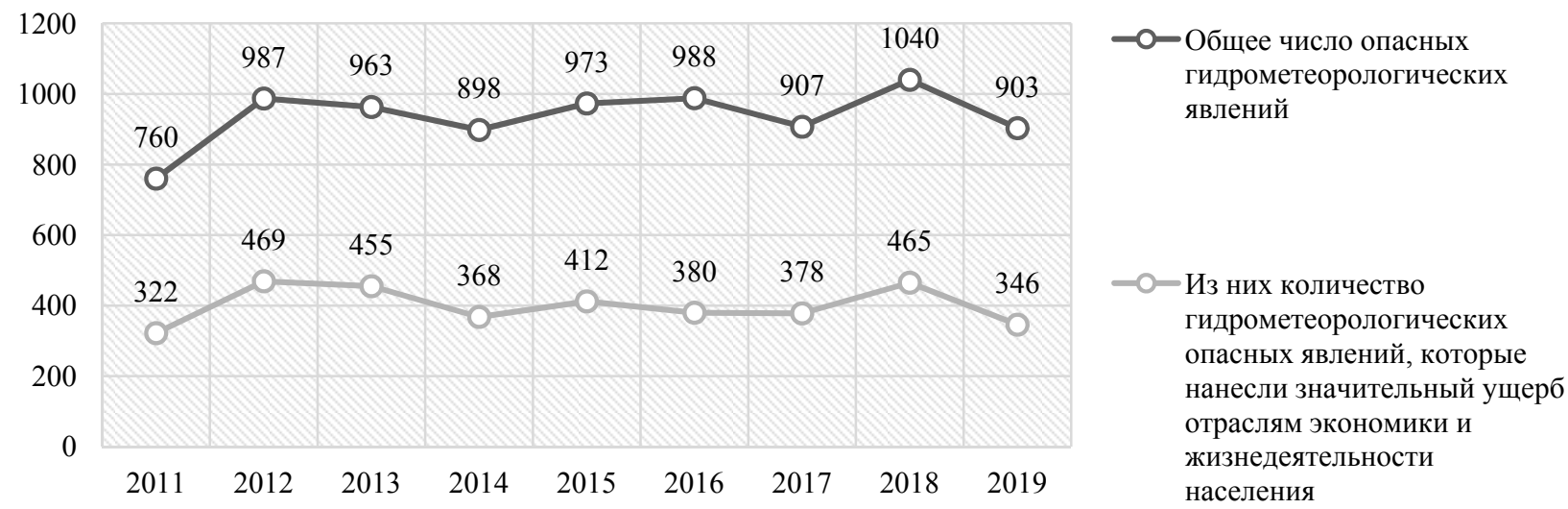

Рис. Динамика количества опасных гидрометеорологических явлений на территории Российской Федерации за 2011-2019 гг.

Источник: Составлено автором на основе данных Росстата [6]

Отечественные и зарубежные авторы широко обсуждают проблемы источников финансирования управления климатической безопасностью[8-12 и др.]. Система финансово-кредитных инструментов включает широкий спектр составляющих.

1. Ориентированная на климатосбережение налоговая политика.

2. Ускоренная амортизация климато- и энергосберегающих основных фондов.

3. Купля-продажа прав на загрязнение.

4. Кредитные отношения, в том числе «зеленые» сертификаты и облигации, экологический лизинг.

5. Климатическое страхование и хеджирование.

6. Резервирование.

7. Бюджетное финансирование (субсидирование и т. д.).

Эффективным финансовым инструментом является климатосберегающая налоговая политика. В развитых странах применяется налогообложение деятельности, связанной с выбросами парниковых газов, а в России - система взимания экологических платежей, где предусмотрены ставки за нормативные и сверхнормативные выбросы загрязняющих веществ, в том числе парниковых газов. Однако низкие ставки эмиссионных платежей в нашей стране обладают слабым стимулирующим и компенсационным эффектом, а их статус не подразумевает исполнение фискальной функции. Преимущества и проблемы введения углеродного налога на основе изучения зарубежного опыта рассматриваются Е.А. Мотосовой и И.М. Потравным [10], Т.Н. Гаврильевой и Т.В. Сивцевой [11], С.А. Рогинко и Г.И. Шмалем [12] и др. Минэкономразвития опубликовало 04 декабря 2018 г. на федеральном портале проектов нормативных правовых актов проект Федерального закона «О государственном регулировании выбросов парниковых газов и о внесении изменений в некоторые законодательные акты», который не был поддержан Советом Федерации. В июне 2020 г. Правительству была направлена новая версия законопроекта. Она содержала ключевые нормы установления прямых выбросов парниковых газов, выдачи разрешений на прямые выбросы и платности прямых выбросов сверх разрешенных объемов. Законопроект предусматривал ряд преференций: применение ускоренной амортизации фондов, участвующих в снижении выбросов парниковых газов, налоговые льготы, зачет затрат на проекты по сокращению выбросов в качестве платы за сверхнормативные выбросы. Но законопроект так и не был принят. 20.02.2021 г. в Государственную думу РФ был внесен другой законопроект - «Об ограничении выбросов парниковых газов», который в итоге был подписан Президентом и зарегистрирован 02.07.2021 г. под № 296-ФЗ (далее - Закон). В Законе закреплены основные понятия климатического регулирования, разграничены полномочия Правительства РФ и федеральных органов исполнительной власти по ограничению выбросов парниковых газов, порядок установления целевых пока- 
зателей, права и обязанности организаций в рассматриваемой сфере и содержит другие рамочные положения. Документ относит к регулируемым организациям только крупных эмитентов, деятельность которых сопровождается выбросами парниковых газов в размере 150 и более тысяч тонн $\mathrm{CO}_{2}$ - эквивалента в год. Единственная закрепленная Законом обязанность таких организаций - учет и предоставление информации о выбросах парниковых газов. За недостоверную или несвоевременно предоставленную информацию, возможно, будут введены штрафы (Минэкономразвития подготовило соответствующие поправки в КоАП). Закон от 02.07.2021 г. № 296-ФЗ вступает в силу 30 декабря 2021 г., но отчеты о выбросах регулируемые организации будут обязаны предоставлять в установленные Законом сроки только после 1 января 2023 г. Ценность принятого Закона с точки зрения стимулирования снижения карбоноемкости экономики пока невелика, но он предусматривает возможности введения целевых показателей и принятия мер поддержки деятельности, в том числе проектной, в области климатической защиты. Речь о введении национальных углеродных налогов или сборов в нем не идет. Тем не менее принятие стимулирующих мер, на наш взгляд, является в ближайшем будущем неизбежным из-за перспективного ужесточения условий международной торговли: в июле 2020 г. Еврокомиссия анонсировала рассмотрение вопроса о введении углеродного сбора на импорт товаров. По мнению экспертного сообщества, такие сборы могут быть введены в период с 2022 по 2025 г. [13] Россия занимает второе место после Китая по объему карбоноемкого экспорта в Евросоюз (порядка 150-200 млн т ежегодно) [13]. Без превентивных усилий по снижению выбросов парниковых газов введение сбора приведет к снижению рентабельности российского экспорта, возможной потере доли рынка ЕС, снижению доходной части федерального бюджета и ВВП. В первую очередь негативные последствия скажутся на базовых секторах народного хозяйства: нефтяная, газовая, угольная промышленность, черная и цветная металлургия, химия и нефтехимия, дополнительная налоговая нагрузка на экспортеров составит от 3,6 до 8,2 млрд евро в год [14].

Введение в России специальных климатических налогов, на наш взгляд, было бы целесообразно только при выполнении двух условий:

- во-первых, ставки налогов должны быть достаточно высокими, чтобы создавать действенные стимулы для снижения уровня выбросов;

- вторым условием является отмена эмиссионных нормативов и экологических платежей по перечню парниковых газов для исключения двойной нагрузки на причинителей климатического ущерба.

Широкий перечень налоговых льгот, предусмотренный в современном российском законодательстве, на наш взгляд, вполне достаточен, поскольку создает необходимую экономическую заинтересованность предприятий во внедрении наилучших доступных технологий, проведении научных исследований и реализации инновационных решений в сфере природоохраны, в том числе климатосбережения. К таким льготам относятся: освобождение в частных случаях от таможенных пошлин природоохранного оборудования; освобождение от уплаты НДС при выполнении организацией научноисследовательских и опытно-конструкторских работ; пониженные тарифы страховых взносов для организаций, деятельность которых заключается в практическом применении результатов интеллектуальной деятельности; инвестиционный налоговый кредит при проведении научно-исследовательских или опытно-конструкторских работ либо технического перевооружения производства, направленных на защиту окружающей среды от загрязнения промышленными отходами и т. д.

В концептуальном плане инструменты ужесточения налоговой политики, по мнению автора, не должны считаться приоритетным в экономическом механизме, поскольку антропогенный вклад в климатические изменения относительно мал: 25 \% парникового эффекта вызвано содержанием в атмосфере парниковых газов, а антропогенное увеличение их концентрации служит только фактором усиления парникового эффекта, вызываемого в основном водяным паром [15]. Введение национальных сборов за выбросы парниковых газов взамен экологических платежей может усилить стимулирующую функцию и снизить налоговую нагрузку на предприятия, так как выбросы в пределах установленных объемов окажутся бесплатными, а высокие ставки за превышение норм будут эффективно стимулировать к уменьшению карбоноемкости производств до нормативного уровня.

Преимущество в налоговом механизме должно отдаваться развитию налоговых преференций для предприятий, осуществляющих технические и технологические инновации, поскольку именно инновационное развитие чаще всего способствует как снижению уровня образования парниковых газов, так и повышению адаптационного потенциала организаций, территорий, страны. 
Элементом налогового стимулирования можно назвать ускоренную амортизацию природоохранного оборудования, так как она снижает налоговую нагрузку на предприятие, а также способствует обновлению этого оборудования (актуальность инструмента обосновывается, в частности, К.В. Сонных [16]. В РФ законодательством пока не предусмотрено применение данного инструмента к природоохранным фондам, однако он используется для средств, необходимых в научнотехнической деятельности. Для расширения стимулов к внедрению инноваций, в том числе климатосберегающих, нужно расширить применение этой нормы Налогового кодекса РФ к оборудованию, относящемуся не только к фондам, участвующим в снижении прямых выбросов парниковых газов (как это указано в рассмотренном выше законопроекте о введении углеродного сбора), но и к категории наилучших доступных технологий: в настоящий момент к этой категории применяется ускоренная амортизация с повышающим коэффициентом 2, предлагается поднять последний до 3.

Альтернативным инструментом углеродного налога является купля-продажа прав на загрязнение окружающей среды. Она используется в ряде зарубежных стран для регулирования загрязнения атмосферы, водных объектов и земель. В настоящее время на Сахалине планируется провести эксперимент по установлению региональных квот выбросов парниковых газов и торговле ими с целью достижения углеродной нейтральности субъекта РФ к 2025 г. [17]. Эксперты, однако, выражают сомнение относительно реализации этого пилотного проекта, апеллируя, в частности к отсутствию учетной информации об углеродном балансе региона: неизвестно текущее соотношение между выбросами и поглощением парниковых газов, возможно, последние уже превышают первые [18]. Явной проблемой применения данного инструмента в России, на наш взгляд, является двойное «наказание» эмитентов: они вынуждены, во-первых, платить за право выброса парниковых газов, а во-вторых, платить экологические платежи за эти выбросы. Согласно концепции Р. Коуза, который впервые предложил и обосновал данный инструмент, факт покупки компанией права на загрязнение делает ее собственником такого специфического природного блага, как ассимиляционный потенциал окружающей природной среды, что исключает необходимость дальнейшей уплаты за загрязнение. Это означает, что предприятия, купившие квоты на загрязнение, должны освобождаться от уплаты эмиссионных платежей. Еще одна проблема в применении данного инструмента - это определение лимитов загрязнения каждого региона парниковыми газами, которые далее должны распределяться между предприятиями посредством торгов. Чтобы сохранить углеродный баланс, требуется оценить не только ассимиляционный потенциал территорий, но и объемы трансграничного переноса вредных веществ, что довольно трудно с метрологических позиций. А что делать в случае, если окажется, что промышленность территории осуществляет выбросы парников газов сверх расчетных лимитов? Чтобы соблюсти экономические интересы и не закрывать предприятия, потребуется либо устанавливать лимиты выше ассимиляционного потенциала (это нивелирует ожидаемый эффект от данного инструмента), либо оказывать государственную финансовую поддержку по модернизации стратегически значимых предприятий (что может иметь целый ряд негативных последствий от дефицит бюджетов всех уровней до нарушения условий конкуренции на национальных ранках). Данный инструмент ввиду названных недостатков, на наш взгляд, требует глубокой проработки.

Использование лизинга и кредита (углеродного кредита, «зелёных» сертификатов и «зелёных» облигаций), как и всех заемных источников, расширяет возможности для финансирования проектов по снижению выбросов парниковых газов [9]. В нашей стране не сформировалось никаких организационно-правовых и экономических особенностей применения этих инструментов в сфере рационального природопользования и охраны окружающей среды. Отсутствие особых условий ограничивает привлечение заемных средств в климатосберегающую деятельность. На федеральном и региональном уровнях управления предлагается предусмотреть создание при профильных органах исполнительной власти соответствующих структур, которые по заявкам предприятий будут заниматься экспертизой и отбором проектов по снижению выбросов парниковых газов, с предоставлением дальнейшего поручительства в сделке лизинга или кредитовании. Это снизит уровень процентных ставок, увеличит сумму и срок кредитования. Кроме того, можно предусмотреть бюджетное софинансирование самих проектов или процентов по полученным заемным средствам для реализации данных проектов.

Еще одним перспективным инструментом финансирования климатических инвестиций являются «зеленые» облигации, мировой рынок которых появился недавно - около 15 лет назад, но активно растет, и на начало 2021 г. составил 1,05 трлн долл. [19]. В России «зеленые» облигации обращаются менее пяти лет, а к концу 2020 г. их объем составил 186 млрд руб., но по оценке Внешэкономбанка 
РФ суммарный ежегодный прирост в будущем может превысить 300 млрд руб. В иностранных государствах и на международном уровне обсуждаемые долговые бумаги обеспечиваются широкой государственной поддержкой, поэтому высоко котируются (например, объем «климатических» облигаций с инвестиционным рейтингом выше ВВВ на середину 2015 г. составил 266,3 млрд долл.), но имеют, соответственно, довольно невысокую доходность. В качестве барьеров развития отечественного рынка выступают проблемы институционального и регуляторного характера, низкая заинтересованность эмитентов и инвесторов [20]. Поэтому в России нужно развивать нормативно-правовое обеспечение, ускорить принятие национальных стандартов «зеленого», в том числе «климатического» финансирования, создавать условия для привлечения инвесторов.

Страхование и хеджирование климатических рисков большинство исследователей связывают с развитием добровольного и введением обязательного экологического страхования $[5 ; 8 ; 21 ; 22]$ с одной стороны, и применением перспективных форм хеджирования климатических рисков (государственных и корпоративных катастрофных облигаций, погодных фьючерсов, опционов, свопов и форвардных контрактов) $[23 ; 24]$ с другой стороны. Применение страховых инструментов помогает ускорить восстановление хозяйственных систем после наступления событий климатического риска. Кроме того, высокая страховая премия может обеспечить экономические стимулы к проведению проактивной адаптационной политики, действуя как ценовой сигнал на рынке [5]. Ограничивает распространение данного инструмента неразвитость климатического сектора страховых услуг, причинами которой являются неопределенность финансовых последствий событий климатического риска, неоправданного завышения страхователями меры риска и, как следствие, стоимости страховых программ [8].Также сложность оценки меры климатического риска вызывает в свою очередь финансовые угрозы вплоть до банкротства для страховых компаний из-за повышенных обязательств вследствие значительных застрахованных потерь [22]. Для предупреждения завышения или занижения меры риска и цен предлагается (например, на основе положительной практики обязательного автострахования) разработать единую методику расчета страховых премий, которая должна учитывать степень отраслевой уязвимости и территориальной подверженности субъектов природно-климатическим рискам. При условии применения единой методики целесообразным видится введение обязательного климатического страхования для отдельных наиболее уязвимых субъектов экономики. Обязательное страхование повысит ответственность акторов в сфере обеспечения климатической безопасности, создаст условия для предупреждения негативного влияния изменения климата и защиты их интересов в случае необходимости ликвидации последствий опасных гидрометеорологических явлений. Индустрия страхования, возможно, больше, чем какой-либо другой сектор, имеет возможность готовить почву для устойчивых и значительных вкладов в решение проблемы глобального изменения климата [22].

Хеджирование климатических рисков является относительно новым инструментом (впервые в мировой практике был применен в США в 1999 г. [21]). Поэтому до настоящего времени существуют трудности в определении как стандартных, так и свободных условий на климатические контракты, что ограничивает широкое их распространение. Тем не менее в условиях роста волатильности погодных условий и увеличения количества опасных гидрометеорологических явлений хеджирование позволит снизить затраты энергетического, добывающего, инфраструктурного и других секторов экономики, обезопасив их от возможных потерь, связанных с событиями климатического риска. Применение данного финансового инструмента в России рекомендуется апробировать на предприятиях госсектора, сформулировав стандартные условия погодных и температурных биржевыхопционов с участием Федеральной службы по гидрометеорологии и мониторингу окружающей среды (Росгидромет) или ФГБУ «Институт Глобального климата и экологии Росгидромета и РАН». Успешный опыт государственных предприятий даст в дальнейшем стимулы для применения климатического хеджирования в частном секторе.

Сформировать финансовый буфер в управлении климатической безопасностью позволит создание бюджетных и/или внебюджетных резервных фондов как инструмента компенсации ущерба от последствий проявления климатических рисков [25]. Бюджетный резервный целевой фонд можно создать за счет климатических сборов при их введении.

Для преодоления дефицита финансовых ресурсов при реализации масштабных проектов в стратегических отраслях целесообразно предусмотреть субсидирование или беспроцентные бюджетные ссуды, в привязке к обязательствам по сокращению выбросов парниковых газов со стороны получателей средств - природопользователей. Интересен опыт ряда зарубежных стран (Великобритании, США, 
Японии и других) по созданию государственных «зеленых» инвестиционных банков для целевого финансирования или софинансирования национальных, региональных или местных экологических проектов, в том числе проектов, направленных на повышение энергоэффективности, развитие экологически чистого транспорта, адаптации к изменению климата и др. [26]. В отличие от субсидирования, этот инновационный финансовый инструмент ориентирует участников на получение выгоды от проектной деятельности. Для снижения финансовых рисков реализации климатосберегающих проектов, привлечения дополнительных частных инвестиций в рассматриваемую сферу, создания новых «низкоуглеродных» рабочих мест, роста энергоэффективности и энергобезопасности, повышения устойчивости развития территорий рекомендуется создание «климатического» инвестиционного банка на основе изучения и использования лучших зарубежных практик указанных выше «зеленых» инвестиционных банков.

\section{Совокупность предложений по повышению финансового обеспечения управления климатической безопасностью}

\begin{tabular}{|c|c|}
\hline $\begin{array}{l}\text { Предложения по развитию финансового обеспечения } \\
\text { управления климатическими рисками. }\end{array}$ & $\begin{array}{l}\text { Ожидаемые положительные последствия пред- } \\
\text { ложений. }\end{array}$ \\
\hline $\begin{array}{l}\text { Введение повышенных ставок углеродных сборов } \\
\text { за превышение лимитов при одновременной отмене } \\
\text { эмиссионных платежей за выбросы парниковых } \\
\text { газов. }\end{array}$ & $\begin{array}{l}\text { Повышение стимулов к снижению карбоноемко- } \\
\text { сти хозяйственной деятельности за счет смеще- } \\
\text { ния акцентов на выбросы парниковых газов; со- } \\
\text { кращение финансового бремени по уплате эмис- } \\
\text { сионных платежей для соблюдающих углерод- } \\
\text { ные лимиты предприятий. }\end{array}$ \\
\hline $\begin{array}{l}\text { Создание резервных бюджетных фондов за счет } \\
\text { углеродных сборов и иных поступлений. }\end{array}$ & $\begin{array}{l}\text { Повышение устойчивости финансирования } \\
\text { компенсации ущерба от событий климатическо- } \\
\text { го риска. }\end{array}$ \\
\hline $\begin{array}{l}\text { Применение ускоренной амортизации фондов, } \\
\text { участвующих в снижении выбросов парниковых } \\
\text { газов. }\end{array}$ & $\begin{array}{l}\text { Стимулирование инвестиционной активности } \\
\text { предприятий к внедрению климатосберегающих } \\
\text { технологий. }\end{array}$ \\
\hline $\begin{array}{l}\text { Зачет затрат на проекты по сокращению выбросов } \\
\text { парниковых газов в качестве платы за превышение } \\
\text { лимитов. }\end{array}$ & $\begin{array}{l}\text { Увеличение финансирования инвестиционной } \\
\text { деятельности в области внедрения климатосбе- } \\
\text { регающих технологий. }\end{array}$ \\
\hline $\begin{array}{l}\text { Предоставление поручительства федеральным или } \\
\text { региональным органом исполнительной власти } \\
\text { предприятиям в сделке лизинга или кредитовании по } \\
\text { результатам экспертизы и отбора проектов по } \\
\text { снижению выбросов парниковых газов. } \\
\text { Бюджетное софинансирование самих проектов или } \\
\text { процентов по полученным заемным средствам для } \\
\text { реализации данных проектов, в том числе через } \\
\text { субсидии и государственно-частное партнерство. }\end{array}$ & $\begin{array}{l}\text { Стимулирование инвестиционной активности } \\
\text { предприятий к внедрению климатосберегающих } \\
\text { технологий за счет снижения уровня процент- } \\
\text { ных ставок, увеличения суммы и срока лизинга } \\
\text { или кредитования. }\end{array}$ \\
\hline $\begin{array}{l}\text { Создание «климатического» инвестиционного банка } \\
\text { на базе государственного капитала. }\end{array}$ & $\begin{array}{l}\text { Увеличение государственного и частного инве- } \\
\text { стирования в климатосберегающие проекты, } \\
\text { рост энергоэффективности, рентабельности низ- } \\
\text { коуглеродных производств, создание дополни- } \\
\text { тельных рабочих мест, обеспечение устойчивого } \\
\text { развития. }\end{array}$ \\
\hline $\begin{array}{l}\text { Введение обязательного климатического страхования } \\
\text { с применением единой методики расчета страховых } \\
\text { премий, которая должна учитывать степень отрасле- } \\
\text { вой уязвимости и территориальной подверженности } \\
\text { субъектов природно-климатическим рискам. }\end{array}$ & $\begin{array}{l}\text { Повышение ответственности хозяйствующих } \\
\text { субъектов в сфере обеспечения климатической } \\
\text { безопасности, создание финансовой защиты их } \\
\text { интересов в случае необходимости ликвидации } \\
\text { последствий событий климатического риска. }\end{array}$ \\
\hline $\begin{array}{l}\text { Разработка стандартных биржевых температурных и } \\
\text { погодных опционов и их применение вначале для } \\
\text { госсектора, затем для частного бизнеса. }\end{array}$ & $\begin{array}{l}\text { Предотвращение потерь от событий климатиче- } \\
\text { ского риска у рыночных агентов. }\end{array}$ \\
\hline
\end{tabular}

Источник: Составлено автором. 
В заключение следует отметить, что вызовы совершенствования финансового механизма климатической политики в условиях современных цифровых трендов связаны с развертыванием его информационной поддержки. Недостаточное раскрытие информации природопользователями рассматривается как одно из главных ограничений в стандартизации и использовании «зеленых» кредитов, сертификатов, облигаций [26], а пробелы в информационной поддержке оценки уязвимости и подверженности объектов климатическим рискам служат также барьером к развитию стандартных программ страхования и хеджирования.

Применение мер фискального и нефискального характера, направленных на ограничение выбросов парниковых газов, могут привести к серьезным экономическим последствиям, в том числе росту затрат и снижению рентабельности базовых отраслей экономики России; снижению инвестиционной привлекательности этих отраслей и территорий, где расположены крупнейшие производители; падению доходов населения, снижению благосостояния страны [27]. В современных условиях преодоления мировой экономической рецессии подобные последствия могут усилить разрыв в экономическом развитии Российской Федерации от передовых стран, поэтому целесообразно формировать финансовый механизм климатической политики таким образом, чтобы он носил не сдерживающий, а стимулирующий и компенсационный характер. То есть необходимо постепенно переходить от доминанты прямых методов государственного регулирования климатической безопасностью к гибким рыночным инструментам, в том числе фискальным, побуждающим частных предпринимателей к ответственному и эффективному управлению климатическими рисками [28]. Отобранные по такому принципу инструменты сведены в таблицу.

Таким образом, рекомендованные в рамках настоящего исследования меры совершенствования финансового обеспечения управления климатической безопасностью нашей страны смогут существенно ускорить переход Российской Федерации от карбоноемкого экономического развития к климатосберегающему в долгосрочной перспективе, а в кратко- и среднесрочной - снизить климатические риски функционирования субъектов хозяйственной деятельности, повысить их рентабельность и конкурентоспособность на национальных и международных рынках.

\section{СПИСОК ЛИТЕРАТУРЫ}

1. Pidgeon N., Fischhoff B. The role of social and decision sciences in communicating uncertain climate risks // Nature Climate Change. 2011. Vol. 1,no. 1. P. 35-41.

2. Tong S., Confalonieri U., Ebi K., Olsen J. Managing and mitigating the health risks of climate change: calling for evidence-informed policy and action // Environmental Health Perspectives. 2016. Vol. 124, no. 10. P. A176-A179.

3. Katie Hayes, G. Blashki, J. Wiseman, S. Burke, L. Reifels Climate change and mental health: risks, impacts and priority actions // International Journal of Mental Health Systems. 2018. No. 12 (28).

4. Higgins P.A.T., Harte J. Carbon cycle uncertainty increases climate change risks and mitigation challenges // Journal of Climate. 2012. Vol. 25, no. 21. P. 7660-7668.

5. Botzen W.J.W., Van Den Bergh J.C.J.M. Managing natural disaster risks in a changing climate // Environmental Hazards. 2009. Vol. 8, no. 3. P. 209-225.

6. Федеральная служба государственной статистики. URL: https://rosstat.gov.ru/ (дата обращения: 08.07.2021г.).

7. SvirezhevYu.M., Von Bloh W., Schellnhuber H.-J.Climate impact on social systems: the risk assessment approach // Environmental Modeling and Assessment. 1999. Vol. 4, no. 4. P. 287-294.

8. Keucheyan R. Insuring climate change: new risks and the financialization of nature // Development and Change. 2018. Vol. 49, no. 2. P. 484-501.

9. Бенч Л.Я., Андрийчук А.Ю., Пономарева К.С. Кредитные инструменты как составляющая политики «зелёных» финансов // Бизнес информ. 2019. o. 12 (503). С. 338-343.

10. Мотосова Е.А., Потравный И.М. Плюсы и минусы введения углеродного налога: зарубежный опыт и позиция России по киотскому протоколу // ЭКО. 2014. № 7 (481). С. 180-189.

11. Гаврильева Т.Н., Сивцева Т.В. Риски и механизмы внедрения углеродного налога в России // Экономика Востока России. 2017. № 2 (8). С. 57-63.

12. Рогинко С.А., Шмаль Г.И. Российская нефтяная промышленность и Парижское соглашение: вызовы и риски // Нефтяное хозяйство. 2019. № 9. С. 50-55.

13. Официальный сайт Boston Consulting Group в России. URL: https://www.bcg.com/ru-ru/press/29july2020carbon-challenge-to-russian-exporters (дата обращения: 21.08.2021).

14. Официальный сайт Общероссийской общественной организации «Деловая Россия». URL: https://deloros.ru/ uglerodnoe-samooblozhenie.html. (дата обращения: 21.08.2021). 
15. Малинин В.Н. Глобальный экологический кризис и климат // Ученые записки РГГМУ. 2017. № 48. С. 11-32.

16. Сонных К.В. Экономическое стимулирование в экологической сфере: поиск баланса интересов государства и бизнеса // Нефть, газ и право. 2018. № 2. С. 39-44.

17. Официальный сайт Правительства РФ. URL: http://government.ru/news/41350/(дата обращения: 22.08.2021).

18. Сахалин станет первым регионом в России, где опробуют торговлю квотами на выбросы парниковых газов // Официальный сайт радиостанции BusinessFM. URL: https://www.bfm.ru/news/476627 (дата обращения: 22.08.2021).

19. Официальный сайт Аналитического центра при Правительстве Российской Федерации. URL: https:/ac.gov.ru/ news/page/v-rossii-razvivaetsa-rynok-zelenyh-obligacij-26965 (дата обращения: 21.08.2021).

20. Богачева О.В., Смородинов О.В. Зеленые облигации как важнейший инструмент финансирования «зеленых» проектов» // Финансовый журнал. 2016. № 2. С. 70-81.

21. Салль М.А. Финансы и климатические риски // Труды главной геофизической обсерватории им. А.И. Воейкова. 2012. № 565. С. 7-21.

22. Ross C., Mills E., Hecht S.B. Limiting liability in the greenhouse: insurance risk-management strategies in the context of global climate change // Stanford Journal of International Law. 2007. Vol. 43 A, no. 1. P. 251-317.

23. Голубева О.В. Финансовые инструменты трансферта погодно-климатического риска // Архитектура финансов: антикризисные финансовые стратегии в условиях глобальных перемен: сб. материалов VII Междунар. науч.-практ. конф. 2016. С. 311-315.

24. Кусниева А.Т .Экзотический финансовый инструмент погодные производные и перспективы его применения // Актуальные вопросы права, экономики и управления: сб. ст. XVI Междунар. науч.-практ. конф.: в 2 ч. / отв. ред. Г.Ю. Гуляев. 2018. С. 29-32.

25. Яковлева Е.Н., Яшалова Н.Н., Смирнов А.В. Механизм организационного и финансового обеспечения управления климатической безопасностью // Научный журнал НИУ ИТМО. Серия «Экономика и экологический менеджмент». 2019. № 4 (39). С. 153-164.

26. Худякова Л.С. Международное сотрудничество в развитии «зеленого» финансирования // Деньги и кредит. 2017. № 7. С. 10-18.

27. Аналитический доклад «Риски реализации Парижского климатического соглашения для экономики и национальной безопасности России». М.: Институт проблем естественных монополий, 2016. 114 с.

28. Васильцов В.С., Яшалова Н.Н., Яковлева Е.Н. Модель организационно-экономического механизма управления климатическими рисками в условиях «зеленой» инновационно-ориентированной экономики // Вестн. Удм. ун-та. Сер. Экономика и право. 2019. Т. 29, вып. 6. С. 730-735.

Поступила в редакцию 25.08.2021

Яковлева Елена Николаевна, кандидат экономических наук, доцент, доцент кафедры управления и экономики

Вологодский филиал ФГБОУ ВО Российская академия народного хозяйства и государственной службы при Президенте Российской Федерации

160017 , Россия, г. Вологда, ул. Ленинградская, 71

E-mail: yenm2a@mail.ru

\title{
E.N. Yakovleva
}

\section{FINANCIAL SUPPORT FOR CLIMATE SECURITY MANAGEMENT}

\author{
DOI: 10.35634/2412-9593-2021-31-6-1032-1040
}

In the 21 st century, climate change is becoming a key constraint on the sustainable development of industries, regions, countries, and the world community as a whole. Climate risk management therefore requires increased financial support, both to compensate for the damage caused by hydrometeorological hazards and to implement policies to reduce anthropogenic greenhouse gas emissions and adapt to changes. The article examines the main sources of financing for climate security management in Russia and foreign countries. Their positive aspects and problems of practical use have been identified. Each financial instrument is considered from the point of view of regulatory influence on subjects of market economy and climate risks. It has been shown that a number of elements of fiscal policy used on an ongoing basis or as an experiment in Russia require refinement or replacement. Practical recommendations for improving the situation are proposed, including the use of innovative tools for our country (climate innovation bank, weather and temperature options, etc.). The author's recommendations are aimed at changing the vector of climate regulation from state paternalism to the application of entrepreneurial initiative by creating effective market incentives. The result will be not only a decrease in greenhouse gas emissions and energy intensity of the economy, but also an increase in profitability 
and competitiveness, the investment attractiveness of organizations, territorial entities, the country, as well as an increase in the employment and well-being of the population and national wealth of the Russian Federation.

Keywords: climate security, climate risks, financial resources, taxes, carbon charges, depreciation, credit, insurance, hedging, leasing, reserves.

Received 25.08.2021

Yakovleva E.N., Candidate of Economics, Associate Professor at Department of Management and Economics Vologda branch of RANEPA

Leningradskaya st., 71, Vologda, Russia, 160017

E-mail: yenm2a@mail.ru 